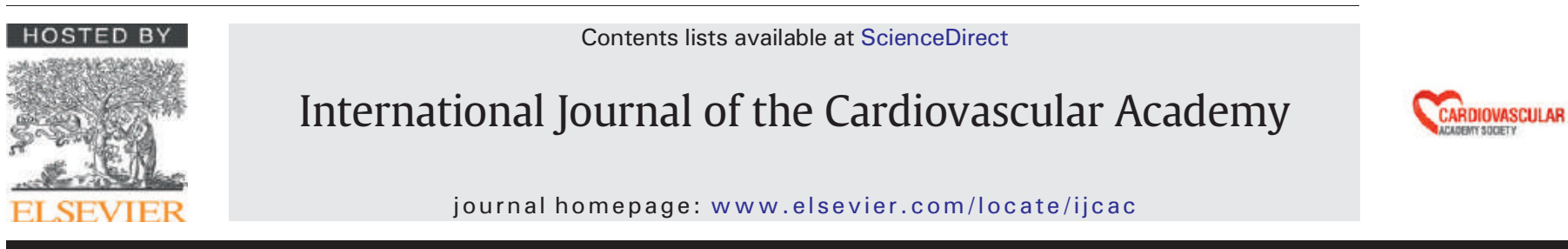

Case report

\title{
Malignant right coronary artery originating from left coronary sinus
}

\author{
Erkan Yildirim ${ }^{\mathrm{a}, *}$, Uygar Cagdas Yuksel a, Baris Bugan ${ }^{\mathrm{b}}$, Murat Celik ${ }^{\mathrm{a}}$, Yalcin Gokoglan ${ }^{\mathrm{a}}$, Ugur Bozlar ${ }^{\mathrm{c}}$ \\ a Gulhane Military Medical Academy, Department of Cardiology, Ankara, Turkey \\ b Girne Military Hospital, Cardiology Service, Girne, Turkish Republic of Northern Cyprus \\ c Gulhane Military Medical Academy, Department of Radiology, Ankara, Turkey
}

\section{A R T I C L E I N F O}

\section{Article history:}

Received 15 November 2015

Accepted 24 November 2015

Available online 15 December 2015

\section{Keywords:}

Single coronary artery

Coronary artery anomalies

Coronary angiography

\begin{abstract}
A B S T R A C T
Congenital coronary artery anomalies are rare and usually an incidental finding during selective coronary angiography. Most of these variations appear to be of no clinical significance but some do have potentially serious sequelae. Anomalous origin of the right coronary artery from the left sinus of valsalva with subsequent coursing between the aorta and pulmonary trunk called "malignant course" is a relatively uncommon congenital defect. In this report we present a patient with a malignant right coronary artery originating from left coronary sinus (C) 2015 The Society of Cardiovascular Academy. Production and hosting by Elsevier B.V. All rights reserved. This is an open access article under the CC BY-NC-ND license (http://creativecommons.org/licenses/by-nc-nd/4.0/).
\end{abstract}

\section{Introduction}

Congenital coronary artery anomalies are rare and usually an incidental finding during selective coronary angiography. The incidence of coronary anomalies was reported as $1.3 \%$ in a large registry of patients undergoing coronary angiogram. ${ }^{1}$ When there is only one coronary artery arising from the aortic trunk by a single coronary ostium the condition is called single coronary artery (SCA). Most of these variations appear to be of no clinical significance but some do have potentially serious sequelae. ${ }^{2}$ Anomalous origin of the right coronary artery from the left sinus of valsalva with subsequent coursing between the aorta and pulmonary trunk called "malignant course" is a relatively uncommon congenital defect. The prevalence rate for the RCA branching from the left coronary sinus was reported as $0.43 \%$ in patients undergoing computed tomography coronary angiography. ${ }^{3}$ Angiography based reports revealed this incidence between 0.03 and $0.17 \% .{ }^{1}$ It is well established that this anomaly can cause angina pectoris, myocardial infarction, or sudden cardiac death in the absence of atherosclerosis. ${ }^{4}$ In this report, we present a patient with a malignant right coronary artery originating from left coronary sinus

\section{Case report}

A 63-year-old man with hypertension and chronic obstructive pulmonary disease was admitted to our clinic for evaluation of atypical chest pain and palpitation. On admission, his blood pressure

\footnotetext{
is There is no conflict of interest

* Corresponding author. Tel.: +90 530 7616398; fax: +90 3928156367 .

E-mail address: dr_erkanyildirim@yahoo.com.tr (E. Yildirim).

Peer review under responsibility of The Society of Cardiovascular Academy.
}

was $120 / 85 \mathrm{mmHg}$ and the pulse rate was 76 beats/min and a 2/6 degree apical pansystolic murmur was heard. The 12-lead electrocardiography (ECG) showed normal sinus rhythm. Transthoracic echocardiography showed a mildly dilated left atrium with mild-to-moderate mitral regurgitation and preserved ejection fraction. Treadmill exercise testing with the Bruce protocol was ambigous. Ambulatory 24 hour ECG showed frequent ventricular extrasystoles (VES). The selective coronary angiography was performed. Right coronary artery was vizualized as anomalously originating from left coronary sinus valsalva (Fig. 1A). The attempt to engage the right coronary catheter to the right coronary artery was unsuccessful and aortic root angiography showed no coronary ostium originating from the right sinus of valsalva. The coronary system was free of significant atherosclerotic disease. 320-slice ECG-gated multidetector computed tomography (prospective gating) showed a right coronary artery originating from left coronary sinus with an interarterial course called "malignant course" (Fig. 1B-C-D). As the stress myocardial perfusion detected no ischemia, the patient was discharged with the medical treatment including beta blocker threapy for frequent VES and has been followed up at the outpatient clinic uneventfully for two years.

\section{Discussion}

When a single coronary ostium provides blood flow for supplying the entire heart, the condition is called SCA. SCA is a rare congenital anomaly of the coronary circulation and is associated with other congenital cardiac malformations such as transposition of the great vessels, coronary arteriovenous fistula, or bicuspid aortic valve. ${ }^{1}$ SCA has generally been regarded as a benign anomaly. The prevalence of anomalous origin and course of coronary arteries is about $0.7-1.96 \% .^{5,6}$ The anomalous origin may have interarterial, retro-aortic, prepulmonic or septal course, the most common being inter-arterial. If RCA course is not 


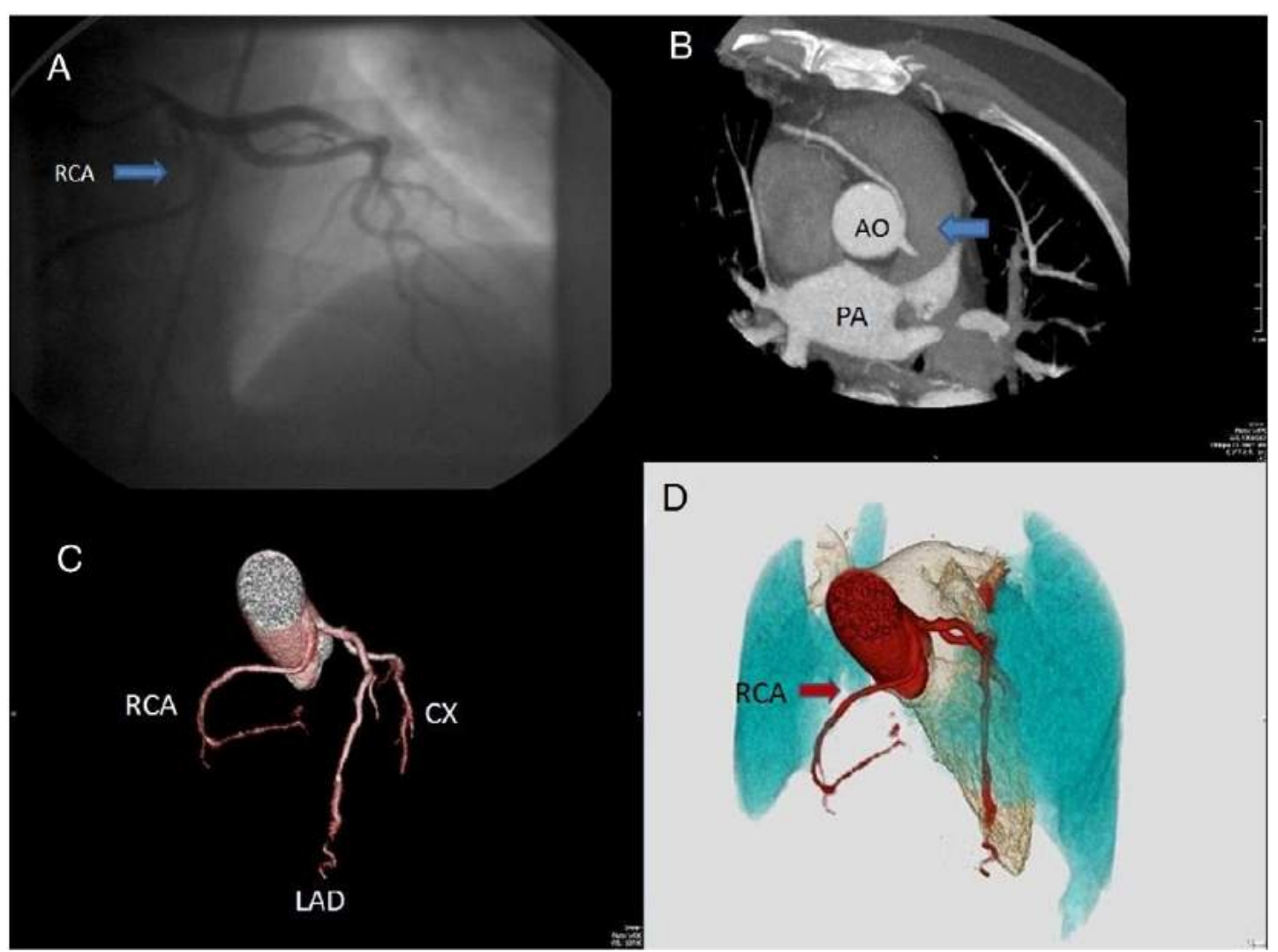

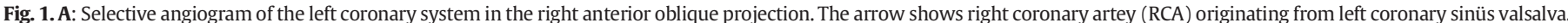

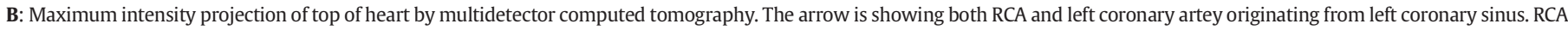

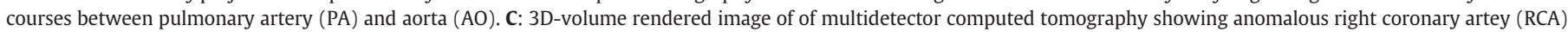

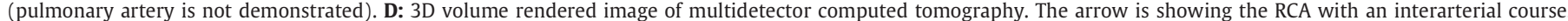
(pulmonary artery is not demonstrated).

between aorta and pulmonary artery, this anomaly is accepted as relatively benign form. A malignant or interarterial course of the right or left coronary artery arising from the opposite coronary sinus has been well described and may have serious sequelae. The interarterial course of a single coronary vessel is subject to compression, which may result in a higher incidence of angina, myocardial infarction, and sudden death. In a majority of previously reported cases, sudden death was triggered by exertion and most of these patients have a positive exercise stress test. ${ }^{7}$ Several factors including acute angulation at the origin, compression of the vessel between the aorta and pulmonary artery, slit like ostium and intramural proximal intussusception of the ectopic artery at the aortic-root wall have been proposed for this association. ${ }^{8}$ The traditional terminology (interarterial course) implies that the aberrant artery was liable to a scissors-like mechanism, created by the close proximity of the aorta and pulmonary artery. Compared with invasive angiography, multidetector computed tomography allows a more accurate depiction of the origin and course of the anomalous coronary artery. In combination with stress myocardial perfusion, multidetector computed tomography can provide an accurate diagnosis and a complete anatomic and functional assessment of this potentially lethal anomaly to guide patient management. ${ }^{9,10}$ The prognosis in single coronary artery is unclear. The incidence of sudden death with this anomaly is estimated at $25-40 \%$ and is associated with exercise in most of the reported cases. ${ }^{11}$ Revascularization is recommended for documented coronary ischemia in the setting of an anomalous coronary artery coursing between aorta and pulmonary arteries by American College of Cardiology and American Heart Association (ACC/AHA) guidelines for congenital heart diseases. ${ }^{12}$ In the present case we decided a conservative strategy, as the patient lived uneventfully for 70 years and there was no documented ischemia with SPECT myocardial perfusion imaging.

\section{Conclusion}

Most of these variations appear to be of no clinical significance but some do have potentially serious sequelae. Anomalous origin of the RCA from the left sinus of valsalva with subsequent coursing between the aorta and pulmonary trunk is called "malignant course". It is well established that this anomaly can cause angina pectoris, myocardial infarction, or sudden cardiac death in the absence of atherosclerosis. Revascularization is recommended only if there is substantial atherosclerosis and documented ischemia.

\section{References}

1. Yamanaka O, Hobbs RE. Coronary artery anomalies in 126,595 patients undergoing coronary arteriography. Catheter Cardiovasc Diagn 1990;21:28-40.

2. Angelini P, Velasco JA, Flamm S. Coronary anomalies: incidence, pathophysiology, and clinical relevance. Circulation 2002;105:2449-2454.

3. Erol C, Seker M. Coronary artery anomalies: the prevalence of origination, course, and termination anomalies of coronary arteries detected by 64-detector computed tomography coronary angiography. J Comput Assist Tomogr 2011;35:618-624.

4. Dirksen MS, Bax JJ, Blom NA, et al. Detection of malignant coronary artery anomaly by multi-slice CT coronary angiography. Eur Radiol 2002;12:S177-S180.

5. Yildiz A, Okcun B, Peker T, Arslan C, Olcay A, Vatan MB. Prevalence of coronary artery anomalies in 12,457 adult patients who underwent coronary angiography. Clin Cardiol 2010;33:60-64.

6. Safak O, Gursul E, Yesil M, et al. Prevalence of coronary artery anomalies in patients undergoing coronary artery angiography: a reviewof 16768 patients. A retrospective, single-center study. Minerva Cardioangiol 2015;63:113-120.

7. Basso C, Maron BJ, Corrado D, Thiene G. Clinical profile of congenital coronary artery anomalieswith origin from the wrong aortic sinus leading to sudden death in young competitive athletes. J Am Coll Cardiol 2000;35:1493-1501.

8. Angelini P, Velasco JA, Ott D, Khoshnevis GR. Anomalous coronary artery arising from the opposite sinus: descriptive features and pathophysiologic mechanisms, as documented by intravascular ultrasonography. J Invasive Cardiol 2003;15:507-514. 
9. Datta J, White CS, Gilkeson RC, et al. Anomalous coronary arteries in adults: depiction at multi-detector row CT angiography. Radiology 2005;235:812.

10. Cohenpour M, Tourovski A, Zyssman I, et al. Anomalous origin of left main coronary artery: the value of myocardial scintigraphic and spiral computed tomography scans. Nucl Med Rev Cent East Eur 2006;9:69-71.

11. Frescura C, Basso C, Thiene G. Anomalous origin of coronary arteries and risk of sudden death: a study based on the autopsy population of congenital heart disease. Hum Pathol 1998;29:689-695.
12. Warnes CA, Williams RG, Bashore TM, et al. ACC/AHA 2008 guidelines for the management of adults with congenital heart disease: a report of the American College of Cardiology/American Heart Association task force on practice guidelines (writing committee to develop guidelines on the management of adults with congenital heart disease). Developed in collaboration with the American Society of Echocardiography, Heart RhythmSociety, International Society for Adult Congenital Heart Disease, Society for Cardiovascular Angiography and Interventions, and Society ofThoracic Surgeons. J Am Coll Cardiol 2008;52:e143-e263. 